\title{
Customer Responses to the Point Management Strategy in the Occurrence of Customer Demotion: An Abstract
}

\author{
Hyunju Shin and Riza Casidy
}

\begin{abstract}
The purpose of this study is to investigate the relative influences of the two types of point management strategy, namely, the point expiration and point maintenance strategies, in the context of status demotion. We postulate that in managing a customer's accrued reward points, the point expiration strategy, as opposed to the point maintenance strategy, significantly reduces customer's perceived unfairness, firm avoidance, and patronage reduction. In examining these relationships, we also take customer's individual characteristics into consideration. The level of selfinterest and need to vent are examined as moderating variables in the relationships between the point management strategy and firm avoidance and between the point management strategy and patronage reduction, through perceived unfairness. The current study employs a scenario-based experiment in the airline industry. This study will provide insights into how service organizations can better design status demotion in hierarchical loyalty programs to aid managerial decision-making.
\end{abstract}

References Available Upon Request

\author{
H. Shin $(\bowtie)$ \\ Georgia Southern University, Statesboro, GA, USA \\ e-mail: hshin@georgiasouthern.edu \\ R. Casidy \\ Deakin University, Burwood, Australia \\ e-mail: riza.casidy@deakin.edu.au
}

